\title{
Oct4 to count 2
}

\author{
Anton Wutz ${ }^{1}$ \\ ${ }^{1}$ Research Institute of Molecular Pathology, Dr. Bohr-Gasse 7, 1030 Vienna, Austria \\ Cell Research (2009) 19:917-919. doi: 10.1038/cr.2009.92; published online 3 August 2009
}

In mammals, dosage compensation between the sexes involves the transcriptional silencing of one of the two $\mathrm{X}$ chromosomes in female cells. Thereby, either the paternally or maternally inherited $\mathrm{X}$ chromosome becomes inactivated in a random manner. $\mathrm{X}$ inactivation is initiated in early embryogenesis. The $\mathrm{X}$ inactivation centre $(X i c)$ regulates the initiation of $\mathrm{X}$ inactivation in a developmentally controlled process during early embryogenesis and contains elements that signal the presence of an $\mathrm{X}$ chromosome. The Xic also contains the non-coding Xist RNA, which localizes in cis over the X chromosome and triggers chromosome-wide gene silencing. The present view is that the mechanisms that control $\mathrm{X}$ inactivation converge at the regulation of Xist.

Xist expression has been studied in detail. Xist is repressed by the noncoding Tsix RNA that overlaps the Xist transcription unit in antisense orientation [1]. In female cells, Tsix is required to suppress Xist expression from the one $\mathrm{X}$ chromosome that will remain active. In male cells with only one $\mathrm{X}$ chromosome Xist remains repressed if Tsix is disrupted. This suggests that the presence of two $\mathrm{X}$ chromosomes predisposes female cells for Xist expression [2]. Before upregulation of Xist the $X i c$ regions on the two $\mathrm{X}$ chromosomes pair providing a potential trigger for $\mathrm{X}$

Correspondence: Anton Wutz

Tel: +43-1-79730/3430; Fax: +43-1-7987153

E-mail:wutz@imp.univie.ac.at inactivation $[3,4]$. The current view is that the pairing event is responsible for establishing mutual exclusive outcomes on the active and the inactive $\mathrm{X}$ chromosome.

The molecular basis of pairing has been studied in embryonic stem (ES) cells. Female mouse ES cells possess two active $\mathrm{X}$ chromosomes, one of which becomes inactivated upon differentiation. Previous work by the Lee group has shown that the DNA binding protein CTCF is essential for Xic pairing, which is mediated through a region close to the Tsix promoter [5]. CTCF binds together with the transcription factor YY1 to multiple sites within the Xic, where it might contribute to Tsix regulation [6]. CTCF is expressed throughout ES cell differentiation and, thus, does not fully explain the developmental onset of $\mathrm{X}$ inactivation after the onset of differentiation. Yet, a recent study links Xist regulation and ES cell transcription factors [7].

In their present study, Donohoe and colleagues examine the function of the transcription factors Oct4 and Sox2, which show an expression pattern that is restricted to early ES cell differentiation (for review see [8]), in the developmental regulation of Xist [9]. Bioinformatic analysis reveals putative Oct4 and Sox 2 binding sites within Xist and at the start site and enhancer of Tsix (Figure 1). Binding of the factors is confirmed by chromatin immunoprecipitation. Since Oct4 binding sites are close to CTCF binding sites the authors examine a potential interaction. They observe that
CTCF interacts biochemically with Oct 4 , and Sox 2 can bind YY1 suggesting the formation of a larger complex in ES cells. Importantly, mutation of Oct4 binding sites in the Tsix promoter reduces its transcriptional activity in a reporter assay. These observations implicate Oct4 in the regulation of Tsix. Oct 4 and Sox 2 are downregulated in differentiation of ES cells and, thus, could explain the loss of Tsix expression which in turn could enable of Xist expression and lead to the inactivation of the $\mathrm{X}$ chromosome. This interpretation is strengthened by the observation that Oct4 depletion using siRNAs leads to a reduction of Tsix expression and the expression of Xist from both X chromosomes in differentiated female ES cells. Thus, in this system Oct4 acts as a transcriptional activator of Tsix and a repressor of Xist.

The study further examines the role of Oct4 for Xic pairing. Depletion of Oct4 blocks Xic pairing indicating that Oct4 also is required for this process. The results by Donohoe et al. provide an important step forward for understanding the developmental regulation of $X$ inactivation. The following model can be proposed: Xic-Xic pairing will predispose the cells for Xist expression. Yet, at the initiatial stage strong Tsix expression will prevent Xist upregulation. Upon differentiation Oct4 and Sox 2 expression diminishes and leads to a shutdown of Tsix from one of the two $\mathrm{X}$ chromosomes allowing upregulation of Xist and $\mathrm{X}$ chromosome inactivation. In such a sense Oct 4 could 


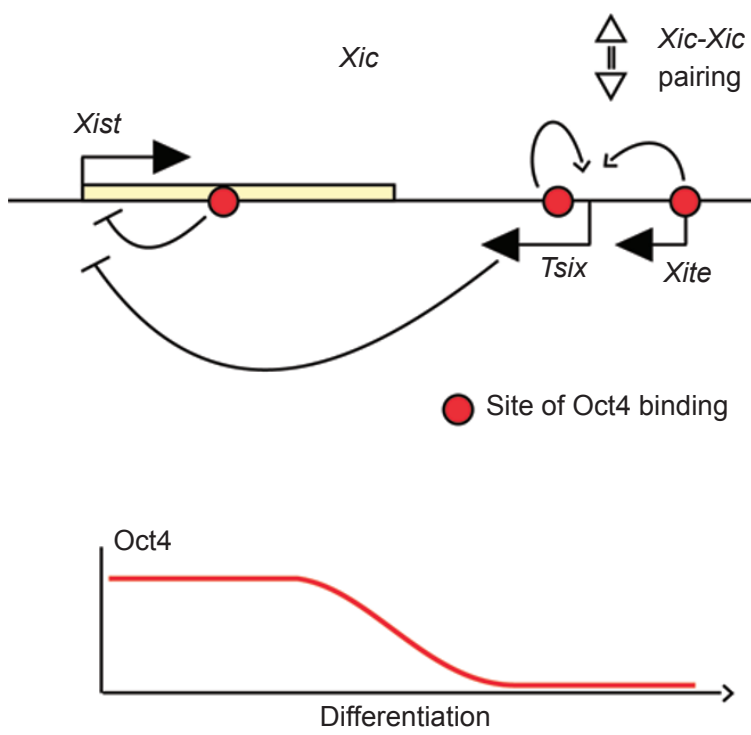

Figure 1 Summary of Oct4 binding in the Xic. A schematic representation of the mouse Xic region indicates the non coding Xist and Tsix RNAs. Oct4 binding to the Tsix promoter and its enhancer Xite activates Tsix, which in turn represses Xist. Down regulation of Oct4 upon differentiation leads to a reduction of Tsix transcription. This allows Xist upregulation from one $X$ chromosome when Xic$X i c$ pairing triggers $X$ inactivation.

provide a candidate for a blocking factor that has been proposed from theoretical considerations to explain how one $\mathrm{X}$ chromosome can be kept active. This is a significant step forward in understanding the regulation of $\mathrm{X}$ inactivation.

The results obtained by Donohoe and colleagues also prompt new questions and will spur further investigation. Among the immediate questions is the function of Oct 4 in pluripotent cells that have already established $\mathrm{X}$ inactivation. Human embryonic stem cells and epiblast derived stem cells from mice have already undergone $\mathrm{X}$ inactivation despite expressing high levels of Oct4 $[10,11]$. Explaining Oct4 function in these different cellular contexts will require the introduction of additional regulatory components. Also the function of the Oct4 binding site in the first intron of Xist is not fully understood. This binding site has been recently found to exert repression of Xist independent of Tsix transcription [7]. This is entirely consistent with its position well within the Tsix transcription unit quite distant to the Tsix promoter, which is also observed by Donohoe et al. but not further examined. It appears likely that Oct 4 contributes to Xist repression in Tsix dependent and independent modes. Ultimately, deletion of the Oct4 binding site in Xist intron 1 will be required for dissecting its contribution to the regulation of $\mathrm{X}$ inactivation. Albeit certain details of the mechanism remain to be elucidated, the data presented by Donohoe et al. make a strong case for Oct4 as an autosomal factor for Xist regulation.

Less clear is the $\mathrm{X}$-chromosomal determinant that enables $\mathrm{X}$ inactivation in female cells. Presently, data indicate that the pairing of Xic regions could perform this function to activate Xist expression. However, a recent study has demonstrated that an X chromosome lacking Xic sequences including Tsix can still be counted and will trigger $X$ inactivation of the other wild type $\mathrm{X}$ chromosome [12]. This strongly argues for an Xlinked activator of $\mathrm{X}$-inactivation that resides outside the Xist-Tsix region.
This activator remains to be identified. The scenario is further complicated by the fact that a region quite distant from Xist and Tsix has been shown to lead to pairing of the $\mathrm{X}$ chromosomes long before initiation of $\mathrm{X}$ inactivation [13]. How this pairing is established and if it is also dependent on Oct4 and CTCF is not known at present. Identification of Oct4 as a regulator of $\mathrm{X}$ inactivation presents a major step forward to address these important questions.

\section{References}

1 Lee JT, Davidow LS, Warshawsky D. Tsix, a gene antisense to Xist at the X-inactivation centre. Nat Genet 1999; 21:400-404.

2 Lee JT, Lu N. Targeted mutagenesis of Tsix leads to nonrandom $\mathrm{X}$ inactivation. Cell 1999; 99:47-57.

3 Bacher CP, Guggiari M, Brors B, et al. Transient colocalization of X-inactivation centres accompanies the initiation of X inactivation. Nat Cell Biol 2006; 8:293-299.

4 Xu N, Tsai CL, Lee JT. Transient homologous chromosome pairing marks the onset of $\mathrm{X}$ inactivation. Science 2006; 311:1149-1152.

$5 \mathrm{Xu}$ N, Donohoe ME, Silva SS, Lee JT. Evidence that homologous X-chromosome pairing requires transcription and Ctcf protein. Nat Genet 2007; 39:1390-1396.

6 Donohoe ME, Zhang LF, Xu N, Shi Y, Lee JT. Identification of a Ctcf cofactor, Yy1, for the X chromosome binary switch. Mol Cell 2007; 25:43-56.

7 Navarro P, Chambers I, KarwackiNeisius V, et al. Molecular coupling of Xist regulation and pluripotency. Science 2008; 321:1693-1695.

8 Ying QL, Wray J, Nichols J, et al. The ground state of embryonic stem cell self-renewal. Nature 2008; 453:519523.

9 Donohoe ME, Silva SS, Pinter SF, $\mathrm{Xu}$ N, Lee JT. The pluripotency factor Oct4 interacts with Ctcf and also controls X-chromosome pairing and counting. Nature 2009; 460:128-132.

10 Silva SS, Rowntree RK, Mekhoubad $\mathrm{S}$, Lee JT. X-chromosome inactivation and epigenetic fluidity in human embryonic stem cells. Proc Natl Acad 
Sci USA 2008; 105:4820-4825.

11 Guo G, Yang J, Nichols J, et al. Klf4 reverts developmentally programmed restriction of ground state pluripotency. Development 2009; 136:10631069.
12 Monkhorst K, Jonkers I, Rentmeester E, Grosveld F, Gribnau J. X inactivation counting and choice is a stochastic process: evidence for involvement of an X-linked activator. Cell 2008; 132:410-421.
13 Augui S, Filion GJ, Huart S, et al. Sensing X chromosome pairs before $\mathrm{X}$ inactivation via a novel $\mathrm{X}$-pairing region of the Xic. Science 2007; 318:1632-1636. 